\title{
Hydro-Magnetic Convection Heat Transfer in a Micropolar Fluid over a Vertical Plate
}

\author{
M. Ferdows ${ }^{1,2 \dagger}$, P. $\mathrm{Nag}^{2}$, A. Postelnicu ${ }^{3}$ and K. Vajravelu ${ }^{4}$ \\ ${ }^{1}$ Quantum Beam Science Directorate, Japan Atomic Energy Agency, Tokai, Ibaraki 319-1195, Japan \\ ${ }^{2}$ Department of Mathematics, University of Dhaka, Dhaka -1000, Bangladesh \\ ${ }^{3}$ Department of Thermo \& Fluid Mechanics, Transilvania University, BdulEroilor, 29, Brasov,2200, Romania \\ ${ }^{4}$ Department of Mathematics, University of Central Florida, Orlando, FL32816, USA \\ $\dagger$ Corresponding Author Email:ferdowsmohammad@yahoo.com
}

(Received September 7, 2011; accepted April 9, 2012)

\begin{abstract}
The combined effect of Hall current, Ohmic heating and suction/injection on the hydro-magnetic free convective heat transfer in a micropolar boundary layer flow past a vertical plate is analyzed. The fluid is assumed to be viscous, incompressible and electrically conducting with a strong magnetic field. Using the modified Ohm's law and the Bossinesq approximation the governing equations of the problem are transformed into a system of non-linear ordinary differential equations by introducing a suitable similarity transformation. The resulting boundary value problem is solved numerically by Nachtsheim-Swigert shooting technique with a sixth order Runge- Kutta iteration scheme. The results are obtained to study the effects of the governing parameters, suction/injection parameter $\left(f_{w}\right)$, magnetic parameter $(M)$, Hall current parameter $(m)$, material parameter $\left(N_{1}\right)$, microrotational parameter $(G)$, the Prandtl number $\left(P_{r}\right)$ and the Brinkman number $\left(B_{r}\right)$ on the transport behaviors of the fluid. That is a parametric study is performed to illustrate the influence of these parameters on the velocity and temperature distribution as well as the local skin-friction and the local Nusselt number. Furthermore, the numerical solutions obtained in this study are compared with the existing results in the literature for some special values of $P_{r}$ and the results are found to be in a good agreement.
\end{abstract}

Keywords: MHD flow, Convection heat transfer, Micropolar fluid, Hall currents, Ohmic heating, Internal heat generation/absorption.

\section{NOMENCLATURE}

\begin{tabular}{|c|c|}
\hline $\mathrm{B}_{0}$ & magnetic field intensity \\
\hline $\boldsymbol{B}$ & magnetic field vector \\
\hline$B_{r}$ & Brinkman Number \\
\hline$C_{p}$ & the specific heat at constant temperature \\
\hline$e$ & the electric charge \\
\hline $\boldsymbol{E}$ & electric field \\
\hline$E_{c}$ & Eckert number \\
\hline$f$ & dimensionless stream function \\
\hline$f_{w}$ & suction/Injection Parameter \\
\hline$g_{0}$ & acceleration due to gravity \\
\hline$g$ & dimensionless lateral velocity \\
\hline$G$ & microrotional Parameter \\
\hline$G_{r}$ & Grashof number \\
\hline$h$ & $\begin{array}{l}\text { non-dimensional micro rotational } \\
\text { velocity }\end{array}$ \\
\hline & current density \\
\hline$k$ & the thermal conductivity \\
\hline$m$ & the hall parameter \\
\hline$M$ & magnetic parameter \\
\hline$n_{e}$ & the number density of electron \\
\hline
\end{tabular}

$\begin{array}{ll}N & \text { angular velocity } \\ N_{1} & \text { material parameter } \\ N_{u} & \text { Nusselt number } \\ p_{e} & \text { electron pressure } \\ P_{r} & \text { Prandtl number } \\ R_{m} & \text { Reynolds number } \\ T & \text { temperature } \\ u, v, w & \text { velocity component along } \\ & \quad \text { velocity vector } \\ \boldsymbol{V} & \text { the cyclotron frequency } \\ w_{e} & \text { quantities at wall } \\ w & \text { cartesian co-ordinates } \\ x, y, z & \text { Angle between the magnetic fieldand } \\ \alpha & \text { the plane transverse to the plate } \\ \beta & \text { Volumetric coefficient of thermal } \\ & \text { expansion } \\ \eta & \text { pseudo-similarity variable } \\ \theta & \text { dimensionless fluid temperature } \\ \lambda & \text { cos }(\alpha)\end{array}$




$\begin{array}{ll}v & \text { kinematic viscosity } \\ \rho & \text { fluid density } \\ \sigma & \text { electric conductivity } \\ \tau_{w x} & \text { local skin-friction coefficient for primary } \\ & \text { velocity } \\ \tau_{w z} & \begin{array}{l}\text { local skin-friction coefficient for secondary } \\ \text { velocity }\end{array}\end{array}$

\section{INTRODUCTION}

The study of MHD natural convection flow and heat transfer of an electrically conducting fluid past a heated semi-infinite vertical plate finds useful applications in many engineering problems such as MHD generator, plasma studies, nuclear reactors, geothermal extractions and the boundary layer control in the field of aeronautics and aerodynamics. It serves as the basis for understanding some of the important phenomena occurring in heat exchange devices. The most important application of MHD is in the generation of electrical power with the flow of an electrically conducting fluid through a transverse magnetic field. Recently, experiments with ionized gases have been performed with the hope of producing power on large scale in stationary plants with large magnetic field. Cryogenic and super conducting magnets are required to produce these very large magnetic fields. Generation of MHD power on a smaller scale is of interest for space application.

The problem of MHD flow over a flat plate is of general interest from the point of view of many applications. Gupta (1960) studied the problem of flow of an electrically conducting fluid near an accelerated plate in the presence of a magnetic field neglecting the effect of Hall current. But when the strength of the magnetic field is very strong, one cannot neglect the effect of Hall current i.e. Hall effect. The Hall effect is the production of a voltage difference (the Hall voltage) across an electrical conductor, transverse to an electrical current in the conductor and a magnetic field perpendicular to the current.

Hall effects on the steady of hydromagnetic flow between two parallel plates have been studied by Sato (1961). With regards to external hydromagnetic flow, Katagiri (1969) discussed the effect of Hall current on the boundary layer flow past a semi-infinite plate. Singh (1964) studied the effect of transverse magnetic field on onedimensional MHD free convection flow past a vertical infinite flat plate whereas Datta et al. (1976) have discussed the oscillatory MHD flow past a flat plate with Hall effects. Further, Hossain et al. (1985) studied the effects of suction and Hall currents on unsteady hydromagnetic flow near an accelerated porous plate. Niranjan et al. (1990) also studied the free convection effects on MHD horizontal channel flow with hall currents. Ram (1988) studied the effects of Hall currents on a steady free convective heat and mass transfer flow through a porous medium. Also combined heat and mass transfer in MHD free convection from a vertical surface with Ohmic heating and viscous $\mu \quad$ coefficient of viscosity

$\mu_{e} \quad$ the magnetic permeability

$\tau_{e} \quad$ the electron collision time

$\psi \quad$ stream function

$\infty \quad$ quantities at the free stream dissipation was studied by Chen (2004). AboEldahabet.al.(2005) discussed viscous dissipation and joule heating effect on MHD free convection from a vertical plate with power-law variation in surface temperature in the presence of hall and ionslip currents.

In this problem micropolar fluid is being considered. Micropolar fluids are those, which contain micro-constituents which can undergo rotation, the presence of which can affect the hydrodynamics of the flow so that it can be distinctly non-Newtonian. It has many practical applications to industries wish to analyze the behavior of exotic lubricants, the flow of colloidal suspensions, human and animal blood and turbulent shear stress.

The theory of micropolar fluids that shows the effects of local rotary inertia and coupled stresses was formulated by Eringen (1966). The theory takes into account the microscopic effects arising from the local structure and micromotions of the fluid elements. The theory can be used to explain the flow of polymeric fluids, paints, ferro-liquids, colloidal fluids, liquid crystals etc. This behavior is familiar in many engineering and physical applications such as power generators, MHD accelerators, refrigeration coils, transmission lines, electric transformers and heating elements. Literature on magneto-micropolar fluid and heat transfer is very extensive due to its technical importance in the scientific community. Some pertinent works in this field are documented by Jena et al. (1981), Gorla et al. (1987) and Gorla (1992). Also, Ortega-Torres et al. (1998) studied the initialvalue problem for the equations of magnetomicropolar fluid in a time dependent domain. Sparrow et al. (1962) were the first investigators to treat the problem of combined convective heat transfer over a horizontal flat plate with the effects of buoyancy forces. Ram et al. (1993) dealt with MHD free convection from an impulsively moving infinite vertical plate in a rotating fluid with Hall and ion-slip currents. Later, Pop and Watanable (1994) studied the effects of Hall current on MHD free convection flow past a semi-infinite vertical plate. Ram (1995) studied the effects of Hall and ion-slip currents on free convective heat generating flow in a rotating fluid. Afterwards, Seddek and Abdelmeguid (2004) have shown Hall and ion-slip effects on magneto-micropolar fluid with combined forced and free convection in boundary layer flow over a horizontal plate. Hady (1996) studied the solution of heat transfer to micropolar fluid from a non-isothermal stretching sheet with injection. Hassanien and Hady (1988) studied micropolar boundary layer flow at a stagnation point on a 
moving wall with suction and injection. Bhargavaet.al.(2004) presented a numerical solution for mixed convection micropolar flow near stagnation point with suction. Rees and Pop (1998)studied free convection boundary layer flow of micropolar fluids from a vertical flat plate, while Mohammadein and Gorla (2001) studied heat transfer in a micropolar fluid over a stretching sheet with viscous dissipation and internal heat generation. Aissa and Mohammadein (2005)studied joule heating effects on a micropolar fluid past a stretching sheet with variable electric conductivity. Rahman and Sattar (2006)studied MHD convective flow of a micropolar fluid past a vertical porous plate in the presence of heat generation/absorption. Soundalgekar and Takhar (1983) studied the flow and heat transfer of a micropolar fluid past a continuously moving plate. El- Arabawy (2003) analyzed the problem of the effect of suction/injection on the flow of a micropolar fluid past a continuously moving plate in the presence of radiation. Yian et al. (2007) discussed the unsteady case for boundary layer flow of a micropolar fluid near a stagnation point with uniform suction/injection.

In the present study, the aim is to investigate the criteria of Hall current, Ohmic heating effects on MHD micropalar fluid and heat transfer from an isothermal vertical plate with suction/injection. Numerical solutions are presented for the velocity components, microrotation and temperature fields by using shooting method. The effects of various parameters of the problem are discussed. The physical interest of the engineering purpose is also discussed using the similarity parameters.

\section{Formulation Of The Problem}

Consider a steady, viscous, incompressible magneto-hydrodynamic (MHD) free convective heat transfer at a semi-infinite vertical plate. The fluid is assumed to be electrically conducting. Also, the presence of strong magnetic field with the effects of Hall current and joule heating is assumed. The vertical plate is maintained at a constant temperature $T_{w}$ and is immersed in a micropolar fluid of temperature $T$ (where $T_{w}>T$ ). The flow is assumed to be in the $x$-direction which is taken along the plate vertically upward and the $y$-axis is normal to it. The effect of Hall current gives rise to a force in the $z$-direction, which induces a cross flow in that direction and hence the flow becomes three dimensional. To simplify the analysis, we assumed that there is no variation in the flow field and the heat transfer quantities in the $z$-direction, results the Eqs. (4)- (9) in 2-D. Fluid property variations are limited to a density, which is taken into account as it affects the buoyancy term. That is, the Boussinesq approximation is applied invoked. Following Ram (1988), a strong uniform magnetic field $\boldsymbol{B}$ of strength $B_{0}$ is applied in a direction that makes an angle $\alpha$ with the plane transverse to the plate which is assumed to be electrically nonconducting, such that $\boldsymbol{B}=(0$, $\lambda B_{0}, \sqrt{1-\lambda^{2}} B_{0}$ )where $\lambda=\cos \alpha$. Thus if $\lambda=1$ the applied magnetic field is normal to the plate while $\lambda=0$ implies that the magnetic field is normal to the plate. Both cases are physically viable and have physical significance. Note that we assumed later $B_{0} \approx x^{-1 / 4}$ getting similarity solution,it does not reflect our assumption $\boldsymbol{B}=(0$, $\lambda B_{0}, \sqrt{1-\lambda^{2}} B_{0}$ ) because this just considered the direction of magnetic field following Ram (1988). The flow configuration and the coordinate system of the problem are shown in Fig. 1.

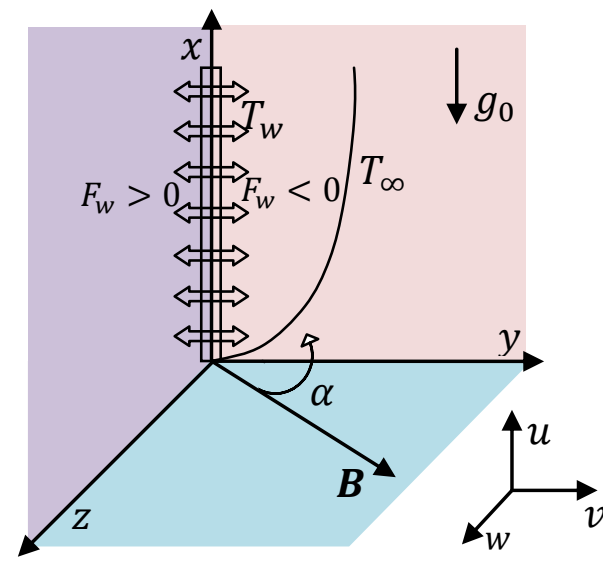

Fig. 1. Flow configuration and coordinate system

Here we assume that the induced magnetic field is produced by the motion of the electrically conducting fluid and is negligible in comparison to the applied magnetic field $\boldsymbol{B}$. This assumption is justified since the magnetic Reynolds number $\left(R_{m}\right)$ is very small for the liquid metals. The conservation of electric charge density $\boldsymbol{\Delta} \cdot \mathbf{J}=0$ gives $J_{y}=$ constantwhere $\boldsymbol{J}=\left(J_{x}, J_{y}, J_{z}\right)$. This constant is zero since $J_{y}=0$ at the plate which is electrically nonconducting. Hence, $J_{y}=0$ everywhere in the fluid. In the present problem it is assumed that there is no external electric field so that the effect of polarization of the ionized fluid can be neglected. We can also assume that the electric field $\boldsymbol{E}=0$ as in Khedr (2009). This correspond to the case that no energy is added or extracted from the fluid by electrical means.

Thus the generalized Ohm's law taking Hall current into account, in absence of electric field (Bachok and Ishak, 2009) becomes

$$
\begin{gathered}
\boldsymbol{J}+\frac{w_{e} \tau_{e}}{B_{0}}(\boldsymbol{J} \wedge \boldsymbol{B})=\sigma\left[\mu_{e}(\boldsymbol{V} \wedge \boldsymbol{B})+\frac{1}{e n_{e}} \boldsymbol{\nabla}\right. \\
\left.\cdot p_{e}\right]
\end{gathered}
$$

where $\boldsymbol{V}=(u, v, w)$ is the velocity vector and $\sigma, \mu_{e}, w_{e}, \tau_{e}, e, n_{e}$ and $p_{e}$ are respectively the electric conductivity, the magnetic permeability, the cyclotron frequency, the electron collision time, the electric charge, the number density of electron and electron pressure.

Under the assumption of the electron pressure for weakly ionized gas, the thermo electric effect and the ion slip are neglected. Hence Eq. (1) yields 
$J_{x}-w_{e} \tau_{e} \lambda J_{z}=-\sigma \mu_{e} B_{0} \lambda w$

$J_{z}+w_{e} \tau_{e} \lambda J_{x}=\sigma \mu_{e} B_{0} \lambda u$

Hence, solving Eq. (2) and Eq. (3) we get,

$J_{x}=\frac{\sigma \mu_{e} B_{0} \lambda}{1+m^{2} \lambda^{2}}(m u \lambda-w)$

$J_{z}=\frac{\sigma \mu_{e} B_{0} \lambda}{1+m^{2} \lambda^{2}}(u+m w \lambda)$

where $m=w_{e} \tau_{e}$ is the hall parameter.

Under the foregoing assumptions with the Bossinesq approximation, the governing equations of the MHD free convection flow are

Continuity Equation

$\frac{\partial u}{\partial x}+\frac{\partial v}{\partial y}=0$

Momentum Equations

$u \frac{\partial u}{\partial x}+v \frac{\partial u}{\partial y}=v \frac{\partial^{2} u}{\partial y^{2}}+g_{0} \beta\left(T-T_{\infty}\right)$

$$
-\frac{B_{0}}{\rho} J_{z}+K_{1} \frac{\partial N}{\partial y}
$$

$u \frac{\partial w}{\partial x}+v \frac{\partial w}{\partial y}=v \frac{\partial^{2} w}{\partial y^{2}}+\frac{B_{0}}{\rho} J_{x}$

Angular Momentum Equation

$G_{1} \frac{\partial^{2} N}{\partial y^{2}}-2 N-\frac{\partial u}{\partial y}=0$

Energy Equation

$$
\begin{aligned}
u \frac{\partial T}{\partial x}+v \frac{\partial T}{\partial y}=\frac{\kappa}{\rho C_{P}} & \frac{\partial^{2} T}{\partial y^{2}} \\
& +\frac{\sigma \mu_{e} B_{0}{ }^{2} \lambda}{\rho C_{P}\left(1+m^{2} \lambda^{2}\right)}\left(u^{2}\right. \\
& \left.+w^{2}\right)
\end{aligned}
$$

where $J_{x}=\frac{\sigma \mu_{e} B_{0} \lambda}{1+m^{2} \lambda^{2}}(m u \lambda-w)$

and $J_{z}=\frac{\sigma \mu_{e} B_{0} \lambda}{1+m^{2} \lambda^{2}}(u+m w \lambda)$.

The appropriate boundary conditions are

$u=w=0, v=v_{w}, N=0, T=T_{w}$ at $y=0$

and $u=w=N=0, T=T_{\infty}$ as $y \rightarrow \infty$

In the above equations $(u, v, w)$ are the velocity components along the $x, y, z$ directions respectively, $v$ is the kinematic viscosity of the fluid, $g_{0}$ is the acceleration due to gravity, $\beta$ is the volumetric coefficient of thermal expansion, $T \& T_{w}$ are the temperature of the fluid at the plate and far away from the plate respectively, $B_{0}$ is the magnetic field intensity, $\rho$ is the density of the fluid, $N$ is the angular velocity, $k$ is the thermal conductivity and $C_{p}$ is the specific heat at constant pressure.

\section{SIMILARITY SOLUTION}

In solving Eqs. (4)- (8), first the similarity transformation is usedand reduced the system of partial differential equations to ordinary differential equation. For this end, the following local similarity variables are introduced:

$$
\begin{aligned}
& \eta(x, y)=\frac{y}{x}\left(\frac{G_{r}}{4}\right)^{1 / 4} \\
& \psi(x, y)=4 v f(\eta)\left(\frac{G_{r}}{4}\right)^{1 / 4} \\
& w(x, y)=\frac{4 v}{x} g(\eta)\left(\frac{G_{r}}{4}\right)^{1 / 2} \\
& N(x, y)=\frac{4 v}{x^{2}} h(\eta)\left(\frac{G_{r}}{4}\right)^{3 / 4} \\
& \theta(\eta)=\frac{T-T_{\infty}}{T_{w}-T_{\infty}}, G_{r}=\frac{g_{0} \beta\left(T_{w}-T_{\infty}\right) x^{3}}{v^{2}}
\end{aligned}
$$

where, $\eta$ is the dimensionless normal distance, $\psi$ is the stream function, $f$ is the dimensionless stream function, $g$ is the dimensionless lateral velocity, $h$ is the dimensionless micro-rotational velocity, $\theta$ is the dimensionless fluid temperature and $G_{r}$ is the Grashof number.

The stream function $\psi$ is defined by

$u=\frac{\partial \psi}{\partial y}$ and $v=-\frac{\partial \psi}{\partial x}$

Hence we have,

$u=\frac{4 v}{x}\left(\frac{G_{r}}{4}\right)^{1 / 2} f^{\prime}(\eta)$

$v=-\frac{v}{x}\left(\frac{G_{r}}{4}\right)^{1 / 4}\left\{3 f(\eta)-\eta f^{\prime}(\eta)\right\}$

Where a prime denotes the differentiation with respect to $\eta$.

Using the above similarity variables, Eqs. (4)- (8) can be written as

$$
\begin{aligned}
& f^{\prime \prime \prime}+3 f f^{\prime \prime}-2 f^{\prime 2}+\theta \\
& -\frac{M \lambda}{1+m^{2} \lambda^{2}}\left(f^{\prime}+m \lambda g\right) \\
& +N_{1} h^{\prime}=0 \\
& \begin{aligned}
g^{\prime \prime}+3 f g^{\prime}-2 f^{\prime} g & +\frac{M \lambda}{1+m^{2} \lambda^{2}}\left(m f^{\prime} \lambda-g\right) \\
& =0
\end{aligned} \\
& G h^{\prime \prime}-2 h-f^{\prime \prime}=0 \\
& \begin{array}{c}
\theta^{\prime \prime}+3 P_{r} f \theta^{\prime}+\frac{M \lambda}{1+m^{2} \lambda^{2}} B_{r}\left(f^{\prime 2}+g^{2}\right) \\
=0
\end{array}
\end{aligned}
$$

with the transformed boundary conditions 


$$
\begin{aligned}
& \eta=0: f(\eta)=f_{w}, f^{\prime}(\eta)=0, g(\eta)=0, \\
& h(\eta)=0, \theta(\eta)=1 \\
& \eta \rightarrow \infty: f^{\prime}(\eta)=0, g(\eta)=0, h(\eta)=0, \\
& \theta(\eta)=0
\end{aligned}
$$

where

$$
\begin{aligned}
& M=\frac{\sigma \mu_{e} B_{0}^{2} x^{2}}{\rho v}\left(\frac{G_{r}}{4}\right)^{-1 / 2}, N_{1}=\frac{K_{1}}{v}, \\
& G=\frac{G_{1}}{x^{2}}\left(\frac{G_{r}}{4}\right)^{1 / 2}, P_{r}=\frac{\rho C_{P} v}{\kappa}, B_{r}=P_{r} E_{c}, \\
& E_{c}=\frac{16 v^{2}}{C_{P}\left(T_{w}-T_{\infty}\right) x^{2}}\left(\frac{G_{r}}{4}\right), \\
& f_{w}=-\frac{v_{w} x}{3 v}\left(\frac{G_{r}}{4}\right)^{-1 / 4}
\end{aligned}
$$

are the magnetic parameter, the material parameter, the microrotional parameter, the Prandtl number, the Brinkman number, the Eckertnumber, and the $\operatorname{suction}\left(f_{w}>0\right) /$ injection $\left(f_{w}<0\right)$ parameter, respectively. Note that in order to get similarity solution, we take

1) $\quad M \sim x^{2}\left(G_{r}\right)^{-1 / 2} \sim x^{2} x^{3 / 2}=x^{2} \quad$ i.e. to impose $B_{0}(x)=B_{1} x^{-1 / 4}$ where $B_{1}$ is a constant in Chen (2004),

2) $G \sim\left(G_{r} / x^{4}\right)^{1 / 2} \sim(1 / x)^{1 / 2}=x^{-1 / 2} \quad$ i.e. to impose $G_{1}=G_{2} x^{1 / 2}$ where $G_{2}$ is a constant,

3) $E_{c} \sim G_{r} / x^{2} \sim x$ i.e. to impose $T_{w}-T_{\infty}=A x$ where $A$ is a constant,

4) $f_{w} \sim x G_{r}{ }^{-1 / 4} \sim x x^{-3 / 4}=x^{1 / 4}$ i.e. to impose $v_{w}=v_{1} x^{-1 / 4}$, a suction (or injection) velocity, where $v_{1}$ is a constant as in Singh (2002).

The physical quantities of principal interest for the present problem are the local skin-friction coefficients and the local Nusselt number which indicate physically the wall shear stress and the rate of heat transfer respectively.

The equations defining the local skin-friction coefficients $\tau_{w x}$ and $\tau_{w z}$ for the primary and secondary velocities respectively are:

$$
\begin{gathered}
\tau_{w x}=\left.\mu \frac{\partial u}{\partial y}\right|_{y=0}=\left.\mu \frac{4 v}{x^{2}}\left(\frac{G_{r}}{4}\right)^{3 / 4} f^{\prime \prime}(\eta)\right|_{\eta=0} \\
=\sqrt{2} \mu v x^{-2}\left(G_{r}\right)^{3 / 4} f^{\prime \prime}(0) \\
\text { And } \tau_{w z}=\left.\mu \frac{\partial w}{\partial y}\right|_{y=0}=\left.\mu \frac{4 v}{x^{2}}\left(\frac{G_{r}}{4}\right)^{3 / 4} g^{\prime}(\eta)\right|_{\eta=0} \\
=\sqrt{2} \mu v x^{-2}\left(G_{r}\right)^{3 / 4} g^{\prime}(0)
\end{gathered}
$$

The local Nusselt number, $N u_{x}$ is defined by

$$
N u_{x}=-\left.\frac{x}{\left(T_{w}-T_{\infty}\right)} \frac{\partial T}{\partial y}\right|_{y=0}=-\frac{1}{\sqrt{2}}\left(G_{r}\right)^{1 / 4} \theta^{\prime}(0)
$$

Thus from the above definition we have the local skin-friction coefficients proportional to the gradient of the axial velocities are $f^{\prime}(0)$ and $g(0)$, i.e. $\tau_{w x} \infty f^{\prime \prime}(0)$ and $\tau_{w z} \infty g^{\prime}(0)$.

Also the local Nusselt number proportional to the negative temperature gradient at $\eta=0$ is $N u_{x} \infty-$ $\theta^{\prime}(0)$.

Note that there are some papers available in the literature that reported the existence of dual solution. But the corresponding authors considered the mixed convection boundary layer flow which problem does not admit similarity solution. These flows are characterized by the so called buoyancy parameter that provides a measure of the influence of the free convection in comparison with that of forced convection on the fluid flow. Also this parameter delays the separation of the flow and arises the dual solution in mixed convection flow. But in our case we considered only free convection boundary layer flow and do not have buoyancy parameter. Thus the present problem does not have dual solution.

\section{Numerical RESUlts AND DISCUSSION}

The mathematical model defined by the system of transformed differential Eqs. (10)- (13) with the boundary conditions Eq. (14) are solved numerically by the Nachtsheim-Swigert (1965) shooting iteration technique together with the sixth order Runge- Kutta iteration scheme. The results were obtained for different values of the suction/injection parameter $f_{w}$, the magnetic field parameter $M$, the Hall parameter $m$, the microrotational parameter $G$, the material parameter $N_{1}$, the Prandtl number $P_{r}$ and the Brinkman number $B_{r}$. To assess the accuracy of the present numerical data, a comparison of the heat transfer rate $-\theta^{\prime}(0)$ with the previously published paper of Thakar et al. (1990) for $f_{w}=0, M=0, m=0, G=$ $0, N_{1}=0, \lambda=0, B_{r}=0$ neglecting the angular motion has been shown. For different values of the Prandtl number $P_{r}$, the results are observed to bein good agreement.

To study the physical behavior of the flow, the nondimensional primary velocity $\left(f^{\prime}\right)$ and secondary velocity $(g)$, the angular velocity $(h)$ and the temperature $(\theta)$ profiles are depicted in Figs. 2-29 for several sets of values of the parameters. Throughout the calculation $\lambda=1.0$ is fixed, which indicates that the magnetic field is assumed along the transverse direction of the plate. The values of $M$ are taken to be large which corresponds to a strong magnetic field. To be realistic, the values of $P_{r}$ are chosen $0.72,2.0,3.7,7.0,16$ corresponding to air, liquid ammonia, Freon-12, water, Ethyl alcohol at $20^{\circ} \mathrm{C}$ (Cowling, 1957). Also $B_{r}=0.007$ and 0.72 correspond to air and water respectively. 
Other values of the parameters are chosen arbitrarily.

Table 1 Comparison of $-\theta^{\prime}(0)$ for $f_{w}=M=m=$ $G=N_{1}=\lambda=B_{r}=0$ neglecting the angular motion

\begin{tabular}{|c|c|c|c|}
\hline$P_{r}$ & $\begin{array}{c}\text { Thakar } \text { et } \\
\text { al. }(1990) \\
\text { for } \xi=0\end{array}$ & $\begin{array}{c}\text { Present } \\
\text { study }\end{array}$ & $\begin{array}{c}\text { Differences } \\
\text { in \% }\end{array}$ \\
\hline 0.5 & 0.4412 & 0.44120 & $0.000 \%$ \\
\hline 0.733 & 0.5079 & 0.50794 & $0.004 \%$ \\
\hline 0.9 & 0.5465 & 0.54655 & $0.005 \%$ \\
\hline
\end{tabular}

Figures 2 and 3 show the non- dimensional velocity along the plate $\left(f^{\prime}\right)$ and across the plate $(g)$ for different values of the suction/injection parameter $f_{w}$. The effect of suction/injection is to prevent the separation of fluid flow from the wall resulting the velocities and the convection of the fluid to be more uniform within the boundary layer. From these figures it is seen that the increasing $f_{w}$ decrease $f^{\prime}$ and $g$, monotonically and reduce the growth of the boundary layer.

Figure 4 depicts that before vanishing the angular velocity of the fluid changes its direction from negative to positive due to the effect of suction/injection. The angular velocity is increasing and decreasing, respectively, near and away from the porous plate for higher values of $f_{w}$.

Figure 5 displays the reduction of temperature distribution with increasing $f_{w}$.

Figures 6-9 illustrate the velocities and the temperature profiles. From these figures we see the damping effect of the magnetic field. The increasing values of the magnetic field parameter $(M), \quad$ retard the tangential velocity $\left(f^{\prime}\right)$ and accelerate the lateral velocity $(g)$ of the fluid motion. This retardation of the primary velocity $\left(f^{\prime}\right)$ happens because of an accelerating force, which acts in a direction parallel to the plate when Hall and ion-slip currents are absent. Here the reverse flow is observed from the Fig. 6 for $M \geq 0$ away from the wall $(\eta \rightarrow 3.8)$.

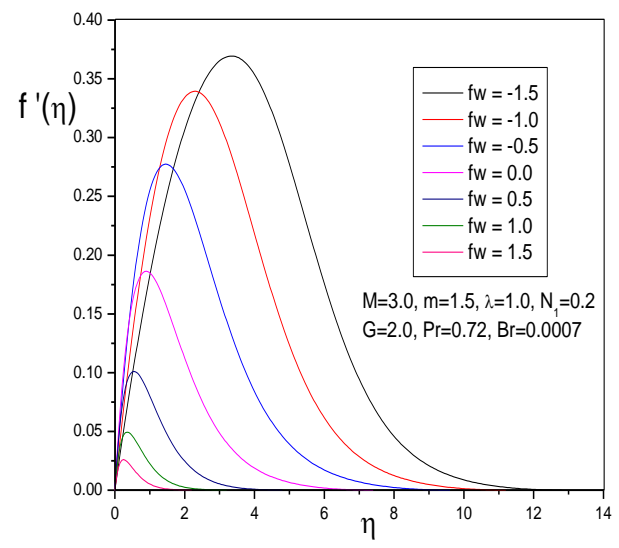

Fig. 2. Primary velocity profiles for increasing values of suction/injection parameter $\left(f_{w}\right)$

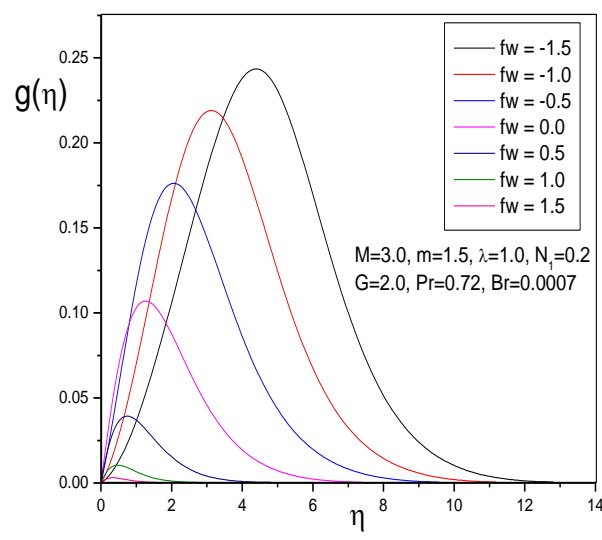

Fig. 3. Secondary velocity profiles for different values of suction/injection parameter $\left(f_{w}\right)$

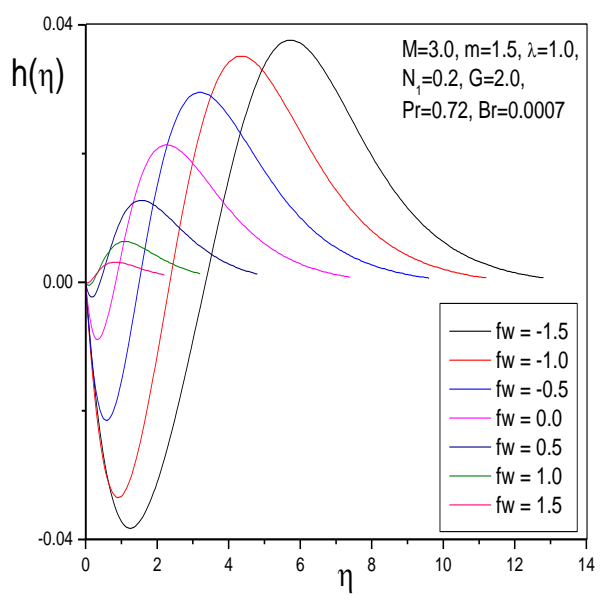

Fig. 4. Angular velocity profiles for different values of suction/injection $\left(f_{w}\right)$

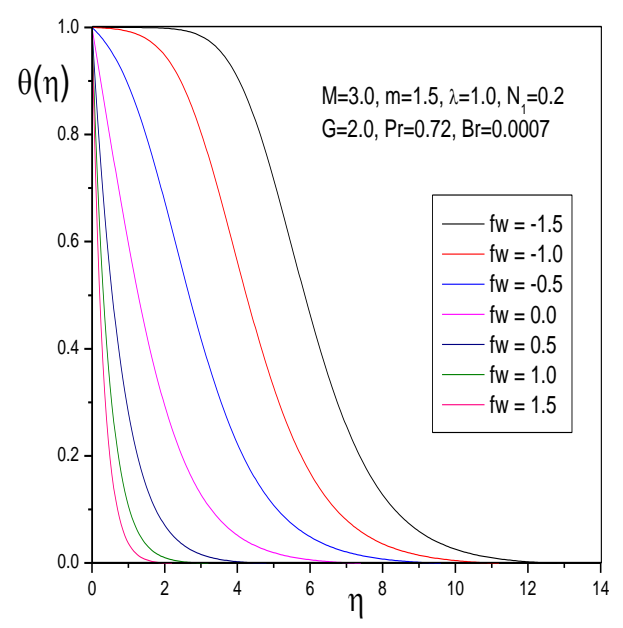

Fig. 5. Temperature profiles for different values of suction/injection parameter $\left(f_{w}\right)$ 


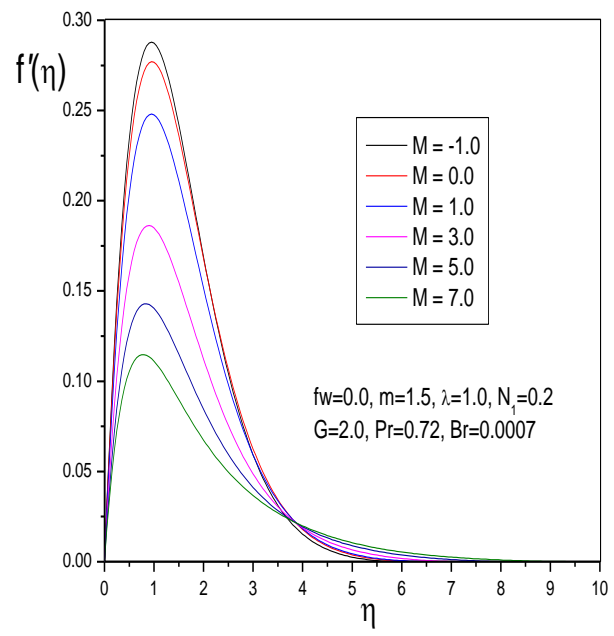

Fig. 6. Primary velocity profiles for different values of Magnetic field parameter $(M)$

From Fig. 7 it is seen that in the absence of magnetic field there is no lateral velocity, which is also found by Abu-Eldahab and El Aziz (2005). It is seen that as $M$ increases the secondary velocity increases for $M \leq 5$ and decreasesfor $M>5$, and the temperature increases due to the hall effect because the effect of viscous heating tends to increase the temperature of the fluid. This effect is more pronounced when strong magnetic field is present.

The fluctuation of primary velocity $\left(f^{\prime}\right)$, secondary velocity $(g)$, angular velocity $(h)$ and temperature $(\theta)$ profile are depicted in Figs. 10-13 for the variation of Hall parameter $m$. The increasing values of $m$ lead to increase the boundary layer thickness which is evident from Figs. 10-12. All the velocities are increasing with an increase in the Hall parameter while the temperature decreases for the higher values of $m$.

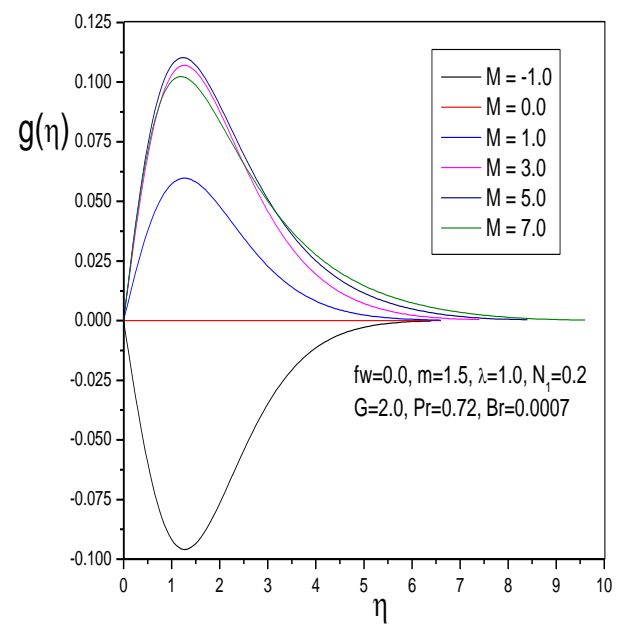

Fig. 7. Secondary velocity profiles for different values of Magnetic field parameter $(M)$

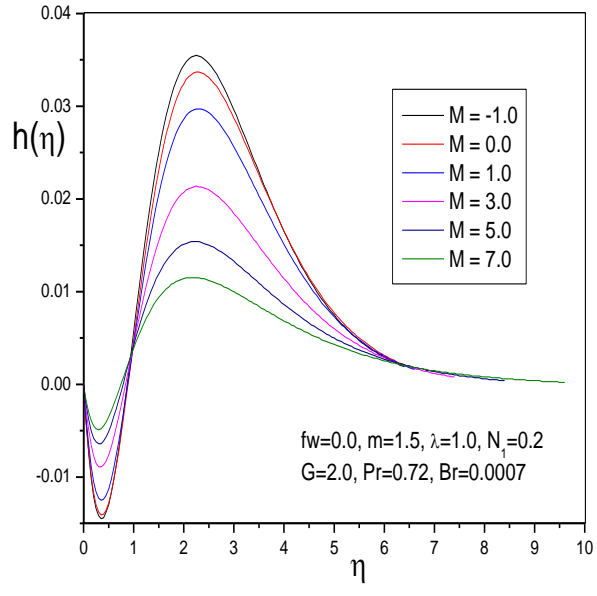

Fig. 8. Angular velocity profiles for different values of Magnetic field parameter $(M)$

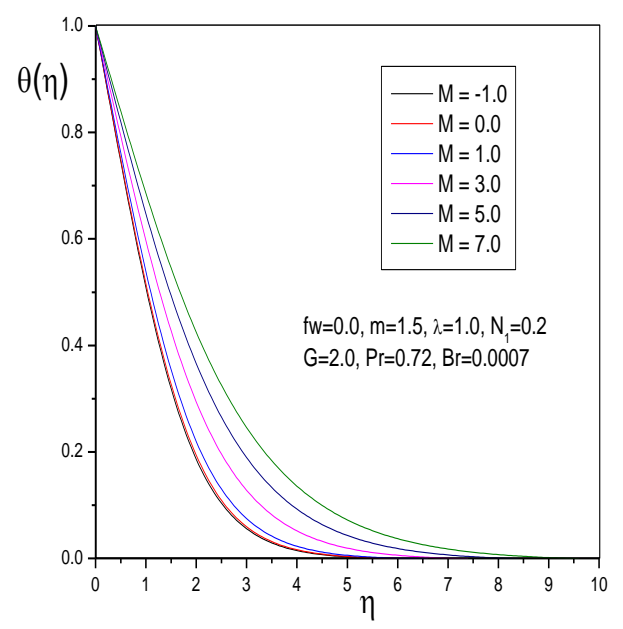

Fig. 9.Temperature profiles for different values of Magnetic field parameter $(M)$

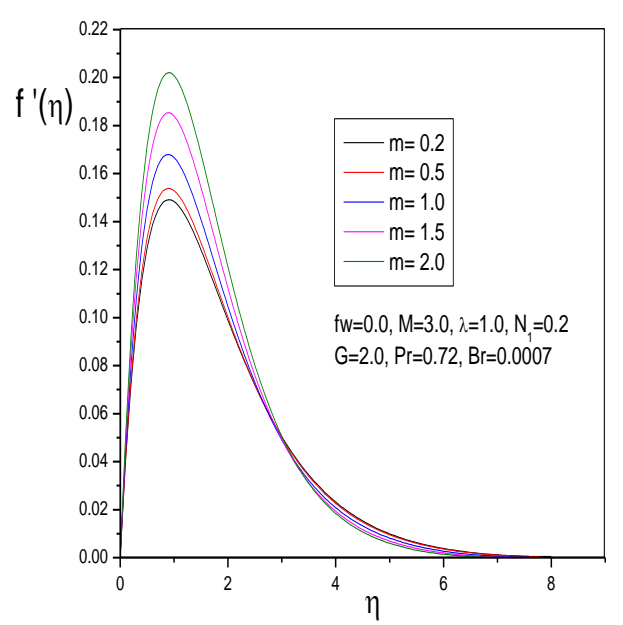

Fig. 10. Primary velocity profiles for different values of Hall parameter $(m)$ 


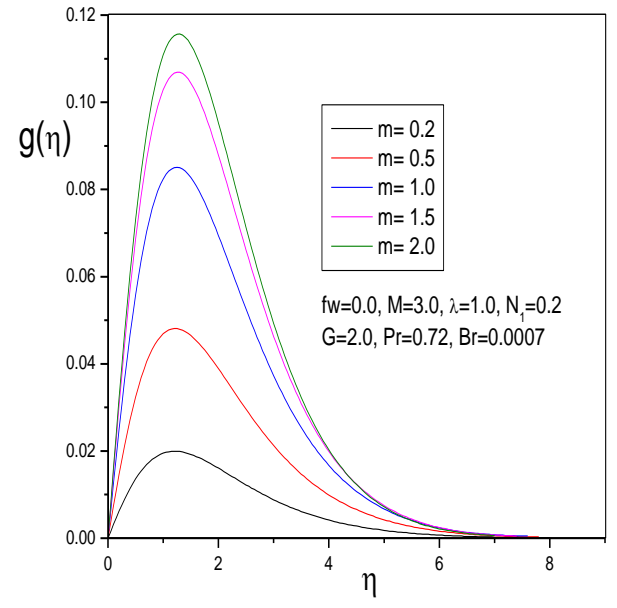

Fig. 11. Secondary velocity profiles for different values of Hall parameter $(m)$

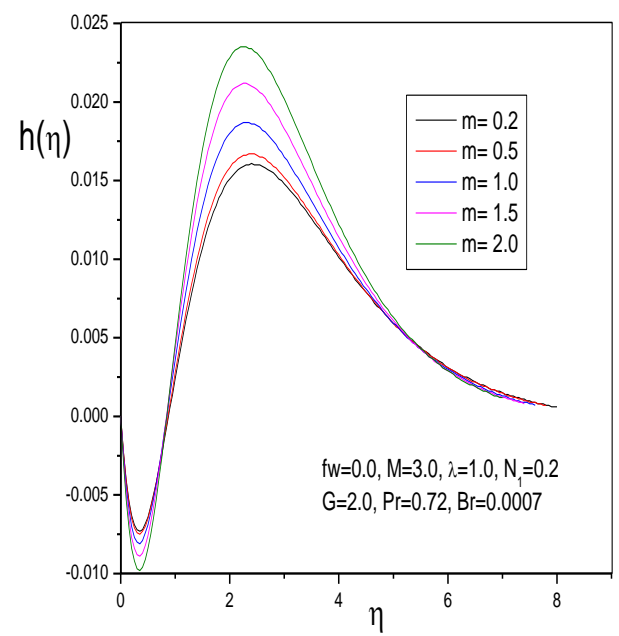

Fig. 12. Angular velocity profiles for different values of Hall parameter $(m)$

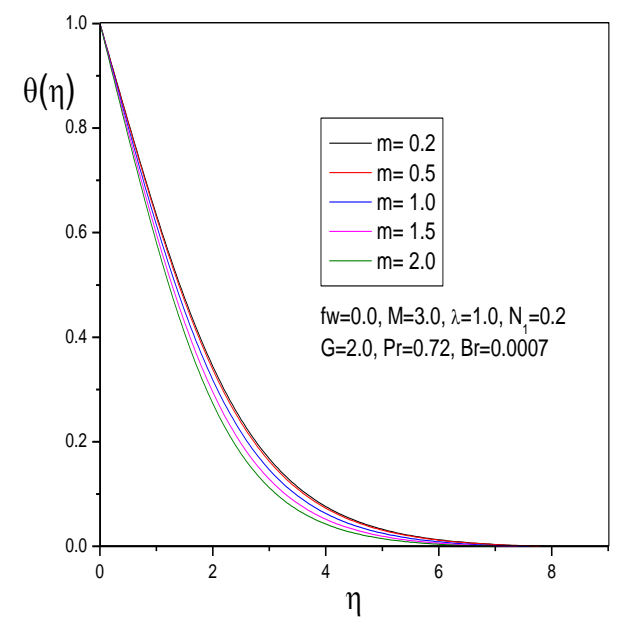

Fig. 13. Temperature profiles for different values of Hall parameter $(m)$
Figures 14-17 depict the non- dimensional velocities $\left(f^{\prime}, g, h\right)$ and temperature distribution $(\theta)$ for several values of the material parameter $N_{1}$. These figures display that with the increasing values of $N_{1}$ the velocities are first increasing near the wall but the situation is completely reversed by decreasing the boundary layer thickness as it moves away from the wall. It is observed from these figures that this occur near $\eta=2$ for tangential velocity $\left(f^{\prime}\right), \eta=1.5$ for lateral velocity $(g)$ and $\eta=3.5$ for angular velocity $(h)$. It is observed from these figures that the material parameter has negligible effect on the nondimensional velocities near the wall.

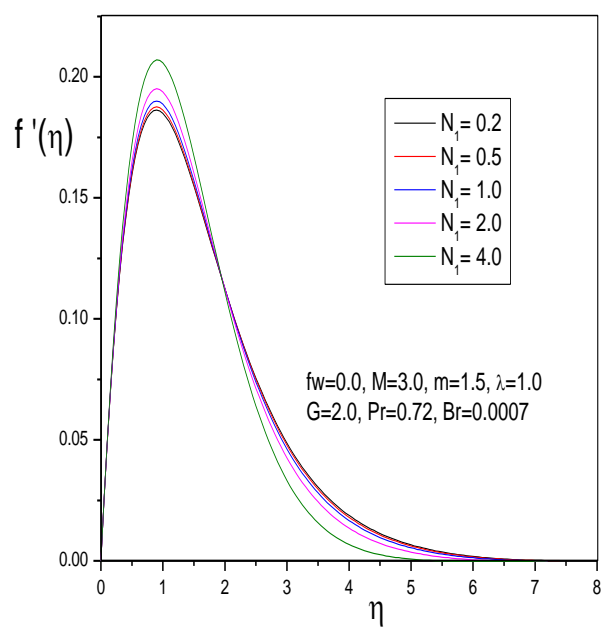

Fig. 14. Primary velocity profiles for different values of material parameter $\left(N_{1}\right)$

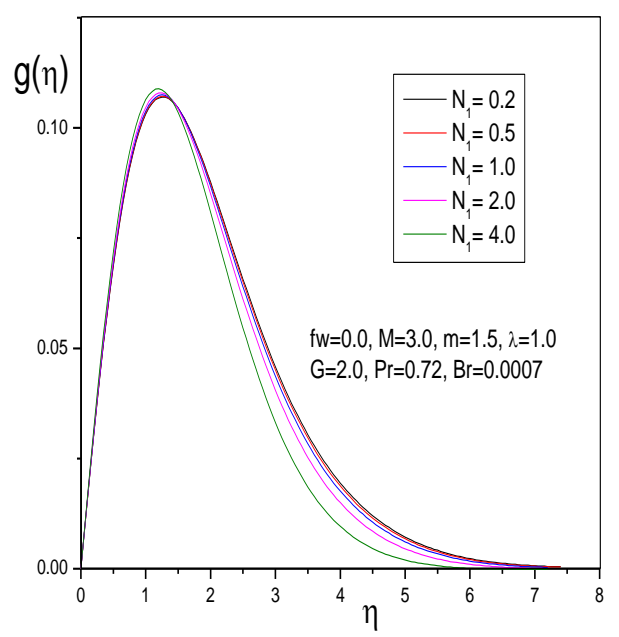

Fig. 15. Secondary velocity profiles for different values of material parameter $\left(N_{1}\right)$ 


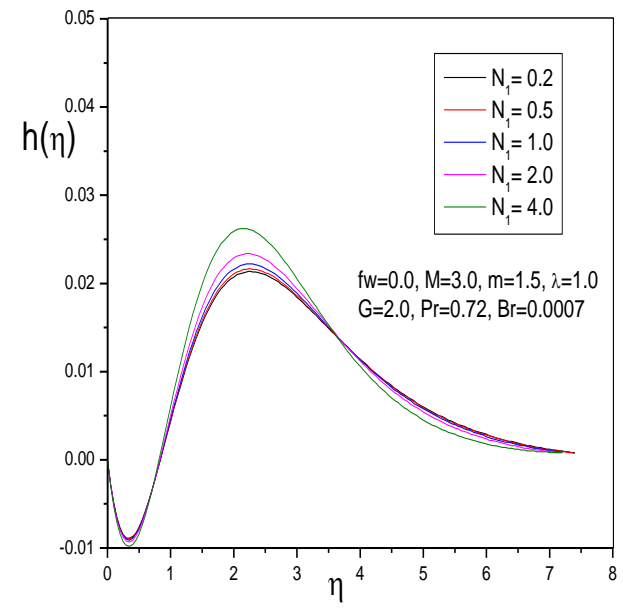

Fig. 16. Angular velocity profiles for different values of material parameter $\left(N_{1}\right)$

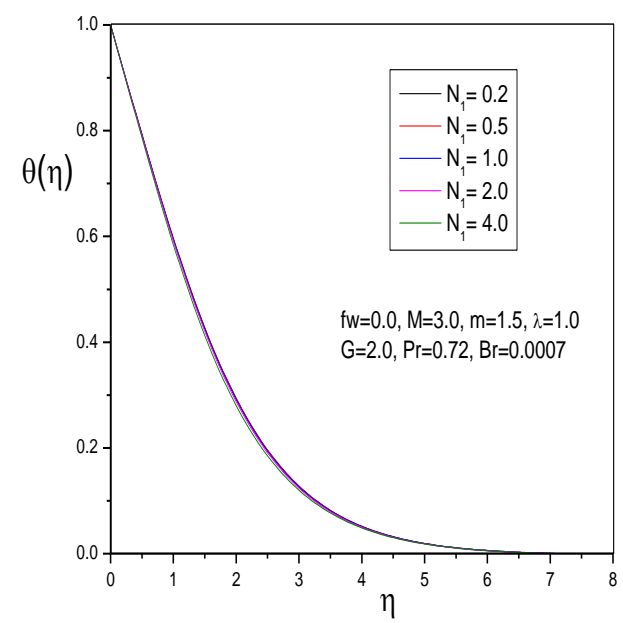

Fig. 17. Temperature profiles for different values of material parameter $\left(N_{1}\right)$

We observe from Figs. 18-21 that the microrotational parameter has no effect on the primary $\left(f^{\prime}\right)$, secondary $(g)$ and temperature distribution $(\theta)$ of the fluid, while it has strong effect on the angular velocity. Figure 20 shows that the angular velocity profiles change their direction from negative to positive near the wall. It is also seen that the values of the maximum amplitude in the negative side is increasing while it is decreasing in the positive side for the higher values of the micro-rotational parameter, $G$.

Figures 22-25 show the effect of increasing values of the Prandtl number $P_{r}$ on the distributions of the non-dimensional velocities and the temperature. It is evident that the primary velocity is decreasing for the higher values of the Prandtl number $\left(P_{r}\right)$ due to the effect of high viscous diffusion.

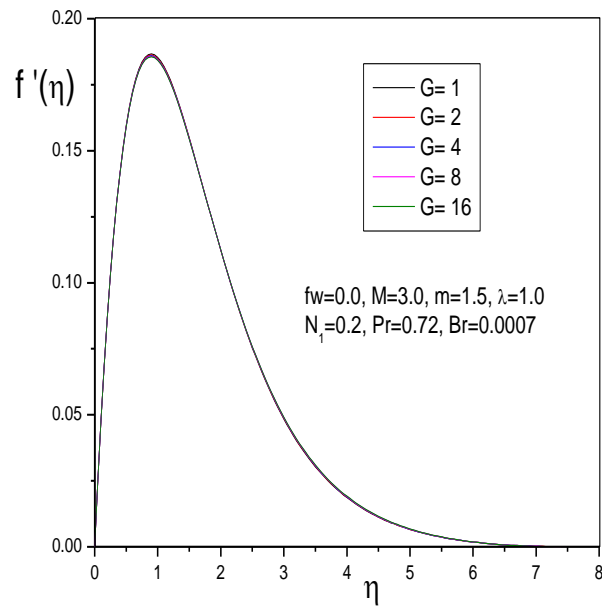

Fig. 18. Primary velocity profiles for different values of micro-rotational parameter $(G)$

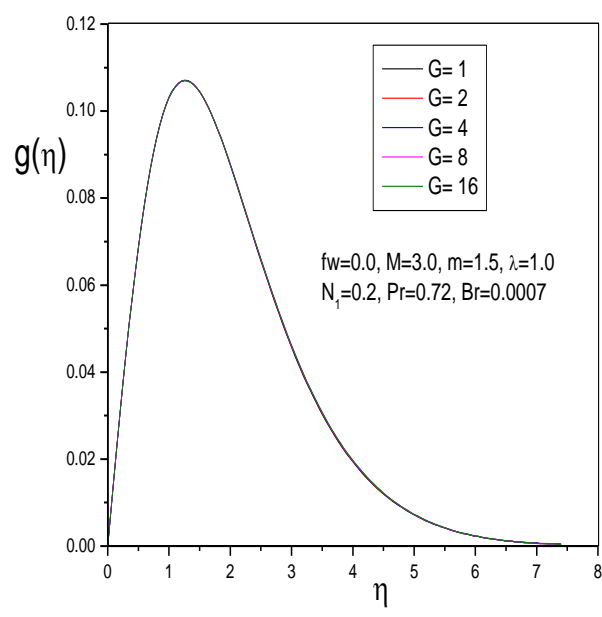

Fig. 19. Secondary velocity profiles for different values of micro-rotational parameter $(G)$

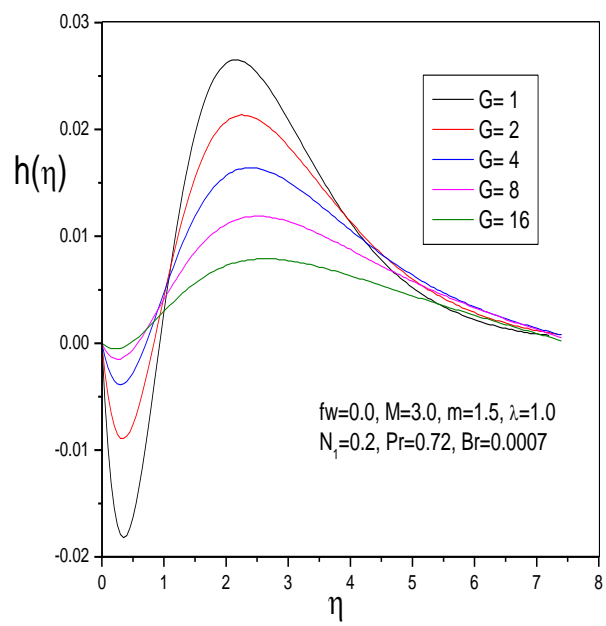

Fig. 20. Angular velocity profiles for different values of micro-rotational parameter $(G)$ 


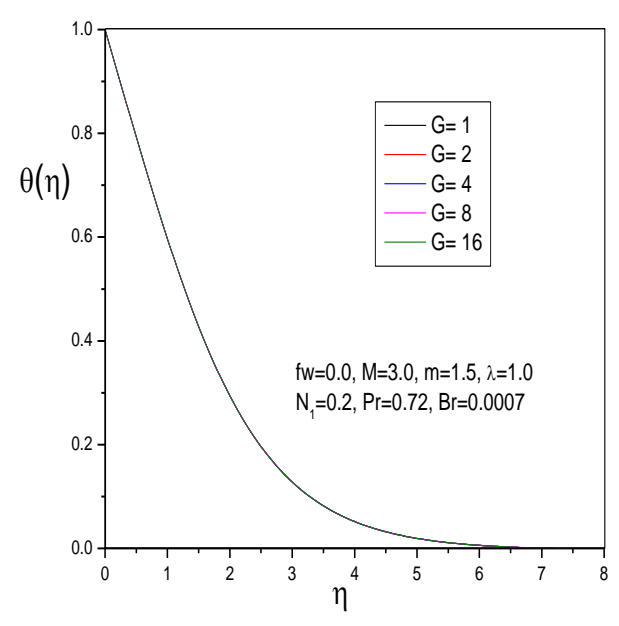

Fig. 21. Temperature profiles for different values of micro-rotational parameter $(G)$

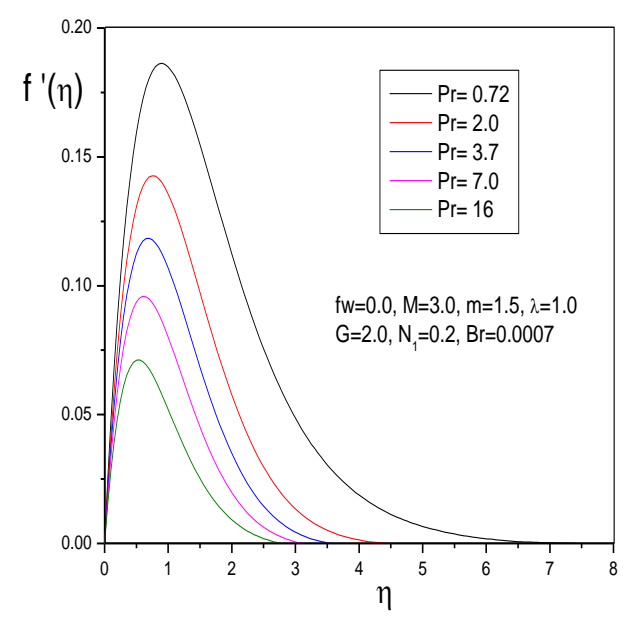

Fig. 22. Primary velocity profiles for different values of Prandtl number $\left(P_{r}\right)$

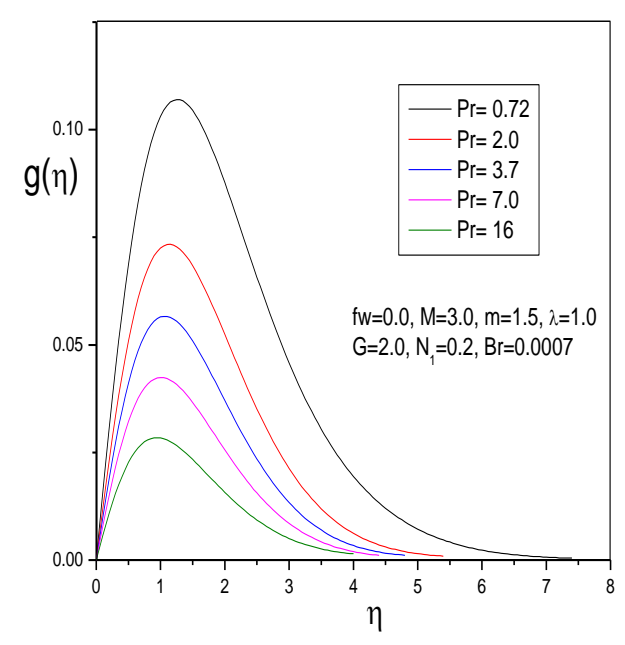

Fig. 23. Secondary velocity profiles for different values of Prandtl number $\left(P_{r}\right)$

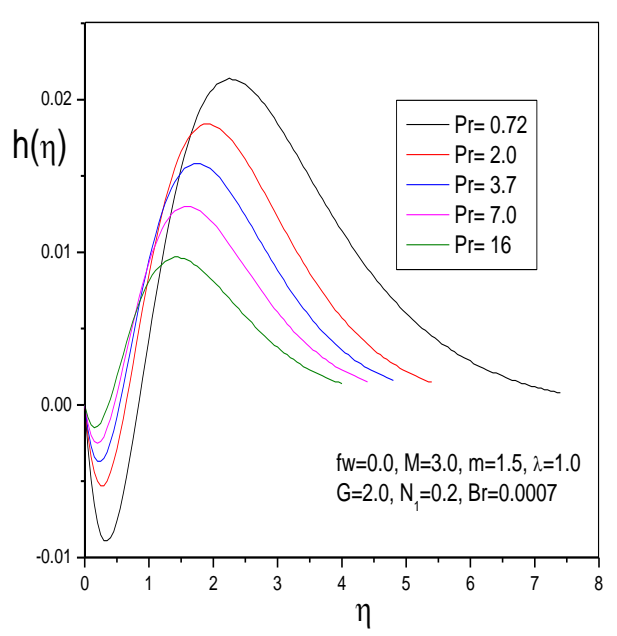

Fig. 24. Angular velocity profiles for different values of Prandtl number $\left(P_{r}\right)$.

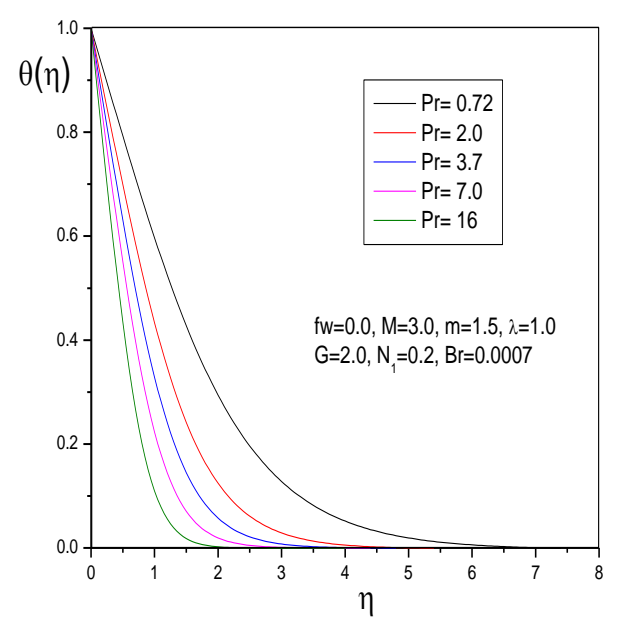

Fig. 25. Temperature profiles for different values of Prandtl number $\left(P_{r}\right)$

The effect of the Prandtl number on the temperature distribution is more pronounced. The higher values of the Prandtl number $\left(P_{r}\right)$ reduce the maximum value of the temperature distribution because of slow thermal diffusion. The angular velocity also maintains the decreasing effect away from the wall for higher values of the Prandtl number $\left(P_{r}\right)$. The variation of the velocities and the temperature profiles are depicted in Figs. 25-28 for different values of the dimensionless dissipation parameter, Brinkman number $\left(B_{r}\right)$. It is observed from these Figures that there is no significant effect of Brinkman number $\left(B_{r}\right)$ between air and water for $f_{w}=0, M=3.0, m=1.5, G=2.0, N_{1}=0.2, \lambda=$ 1.0, $P_{r}=0.72$. But it is evident from the figure that the higher values of $B_{r}$ increase the tangential velocity $\left(f^{\prime}\right)$ and the temperature $(\theta)$ because of joule heating. However for the higher values of the dissipation parameter $\left(B_{r}=8\right)$, a distinctive peak in the temperature profile is noticed in Fig. 28. This implies that the fluid temperature near the wall is greater than the wall temperature and as a result 
there is a heat exchange from the fluid to the wall. Again, near the surface of the plate the secondary and the angular velocity is increasing and decreasing respectively with the increasing values of $B_{r}$ but the reverse is apparent as one move away from the wall.

The numerical values proportional to the local skinfriction coefficients for primary and secondary velocity and the local Nusselt number are depicted as a function of similarity parameters $f_{w}, M, m, N_{1}, G, P_{r}, B_{r}$ keeping $\lambda=1.0$ in Figs. 30 36.

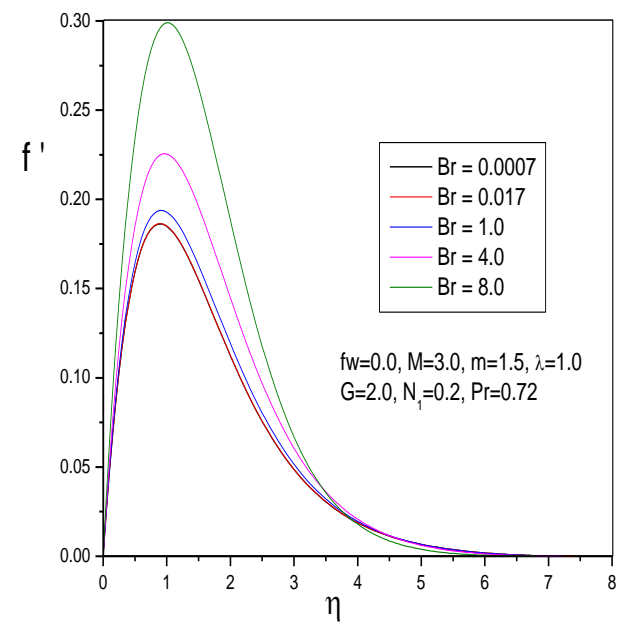

Fig. 26.Primary velocity profiles for different values of Brinkman number $\left(B_{r}\right)$.

Figure 30 shows the effect of suction/injection parameter $f_{w}$, on the local skin-friction coefficients in terms of $f^{\prime \prime}(0), g^{\prime}(0)$, and the local Nusselt number, $-\theta^{\prime}(0)$. It is seen from the figure that for the case of injection, $f_{w}<0$, the local skin-friction coefficients for the axial velocities are decreasing while for the case of suction, $f_{w}>0$, the local skinfriction coefficients are decreasing. That is the maximum value of the local skin-friction coefficients for the primary and secondary velocity occurs within the boundary layer in the absence of suction/injection i.e. $f_{w}=0$. This phenomenon can be explained from Figs. 2-3 that the dimensionless axial velocities are rising nearest to the wall for injection $\left(f_{w}<0\right)$ but the reverse case is true for suction $f_{w}>0$. But the local Nusselt number, $-\theta^{\prime}(0)$, is increasing for both case of suction and injection. This reduction is greater for the case of suction than injection. As a result the local Nusselt number, $-\theta^{\prime}(0)$, is highly increasing when the suction is being applied. But the increasing rate is very slow for injection.

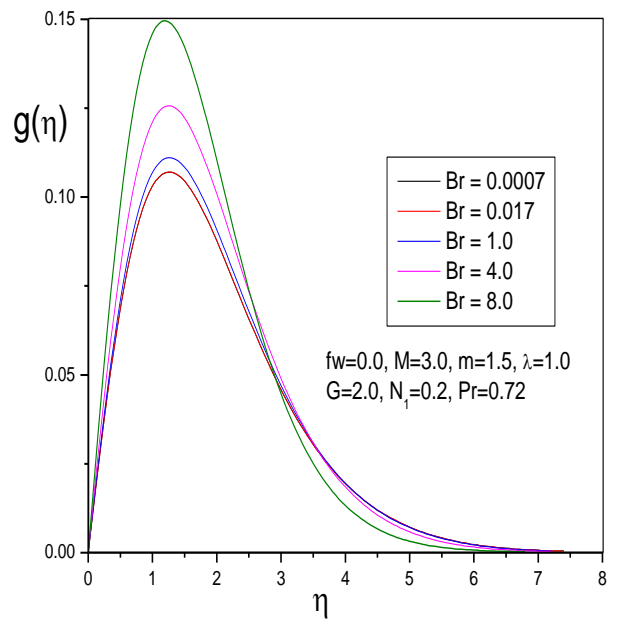

Fig. 27. Secondary velocity profiles for different values of Brinkman number $\left(B_{r}\right)$

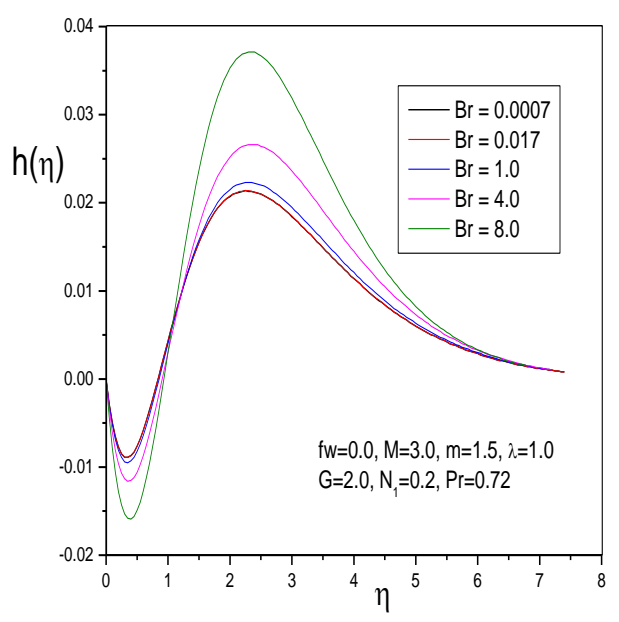

Fig. 28. Angular velocity profiles for different values of Brinkman number $\left(B_{r}\right)$.

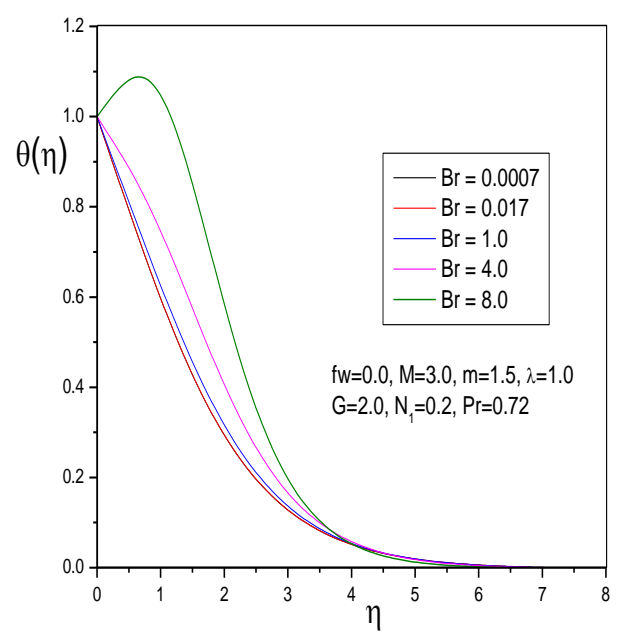

Fig. 29.Temperature profiles for different values of Brinkman number $\left(B_{r}\right)$. 


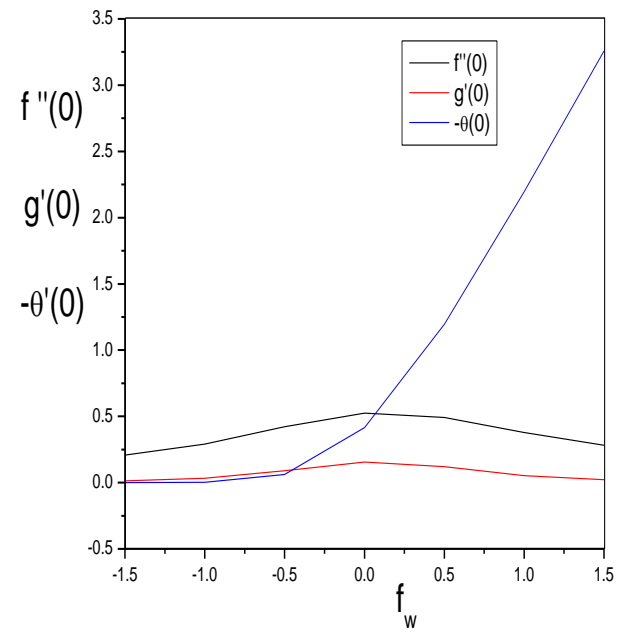

Fig. 30. Effects of $f_{w}$ on the local skin-friction coefficients and the local Nusselt number for

$$
\begin{gathered}
M=3.0, m=1.5, N_{1}=0.2, \\
G=2.0, P_{r}=0.72, B_{r}=0.0007 .
\end{gathered}
$$

The variation of the local skin-friction coefficients for primary and secondary velocity and the local Nusselt number against the magnetic field parameter $\mathrm{M}$, from -1 to 7 (strong magnetic field), is shown in the Fig. 31. It is seen from the figure that the local skin-friction coefficient for primary velocity, $f^{\prime \prime}(0)$, is decreasing with the increasing of the magnetic field strength, as expected, since the applied magnetic field tends to reduce the fluid motion and thus reduce the surface friction force along the plate within the boundary layer. But the local skin-friction coefficient for secondary velocity is increasing from negative to positive with the increasing of $M \leq 5$ and decreasing for $M>5$. The figure also shows the reduction of the local Nusseltnumber as $M$ rises from -1 to 7 because of rising the temperature with the strong magnetic field.

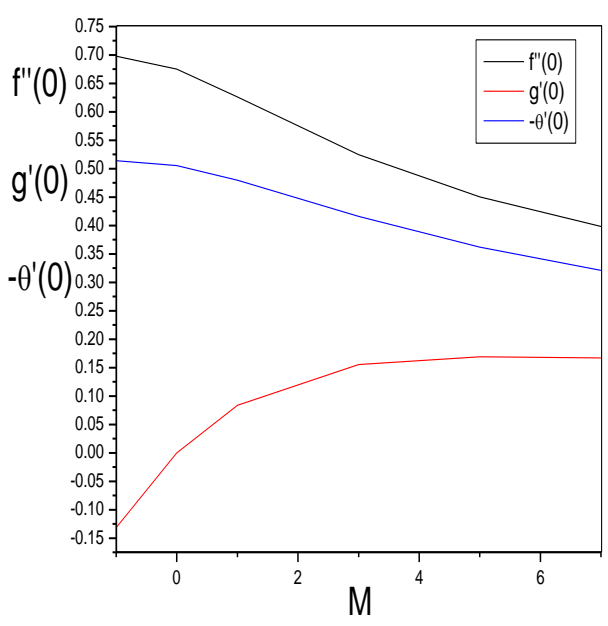

Fig. 31. Effects of $M$ on the local skin-friction coefficients and the local Nusselt number for

$$
\begin{gathered}
M=3.0, m=1.5, N_{1}=0.2, \\
G=2.0, P_{r}=0.72, B_{r}=0.0007 .
\end{gathered}
$$

The effect of varying Hall parameter, $m$, on the local skin-friction coefficients, for tangential and lateral velocity, and the local Nusselt number is shown in Fig. 32. All the physical parameters are increasing with the increasing values of the Hall parameter $m$.

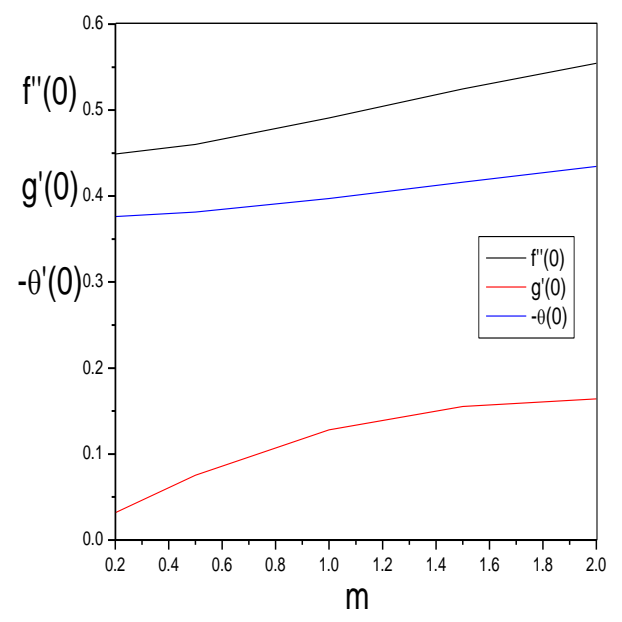

Fig. 32. Effects of $m$ on the local skin-friction coefficients and the local Nusselt number for $M=3.0, m=1.5, N_{1}=0.2$, $G=2.0, P_{r}=0.72, B_{r}=0.0007$.

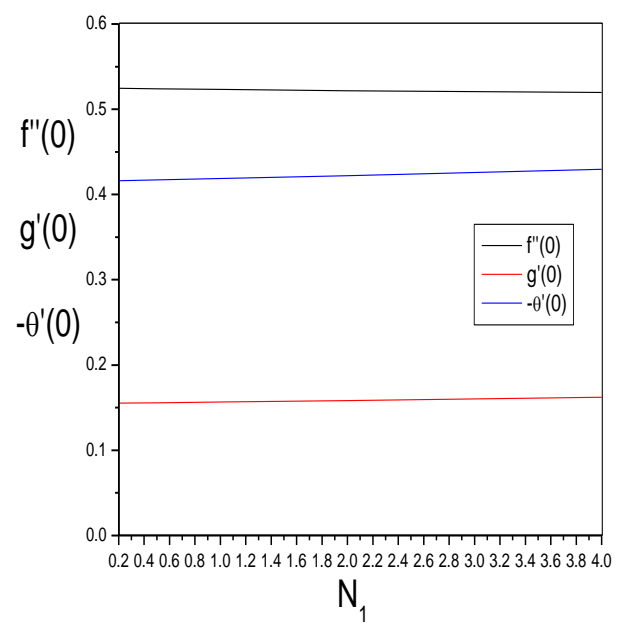

Fig. 33. Effects of $N_{1}$ on the local skin-friction coefficients and the local Nusselt number for

$$
M=3.0, m=1.5, N_{1}=0.2,
$$$$
G=2.0, P_{r}=0.72, B_{r}=0.0007
$$

Figures 33 and 34 are depicted to show the variation of the local skin-friction coefficients due to axial velocities and the local Nusselt number varying the values of material parameter, $N_{1}$, and the values of micro rotational parameter, $G$, respectively. It is observed from the figures that the local skin-friction coefficient for the primary velocity is increasing while that of for the secondary velocity and the local Nusselt number is increasing as $N_{1}$ increases. It is seen from the Fig. 33 that the effect of the material parameter is negligible on the surface 
friction force and surface heat transfer rate. But Fig. 34 illustrates that there is no effect of the micro rotational parameter, $G$, on the physical parameter.

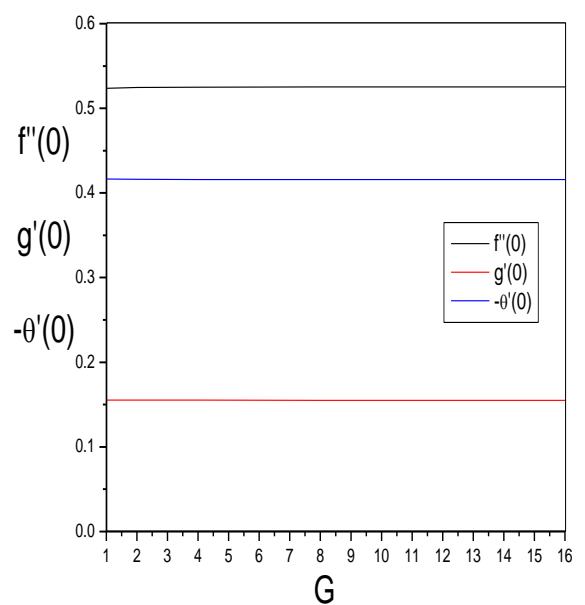

Fig. 34. Effects of $G$ on the local skin-friction coefficients and the local Nusselt number for

$$
\begin{gathered}
M=3.0, m=1.5, N_{1}=0.2, \\
G=2.0, P_{r}=0.72, B_{r}=0.0007
\end{gathered}
$$

Figure 35 shows the effect of the Prandtl number, $P_{r}$, on our interested physical parameter $f^{\prime \prime}(0)$, $g^{\prime}(0)$ and $-\theta^{\prime}(0)$. The figure depicts that the local skin-friction coefficients, $f^{\prime \prime}(0) \& g^{\prime}(0), \quad$ is decreasing while the local Nusselt number is increasing with the increasing values of the Prandtl number, $P_{r}$. This behavior happened due to the effect of high viscous diffusion and the slow thermal diffusion. The high viscous diffusion prevents to increase the axial velocities near the wall and, as a result the wall friction force is decreasing. On the other hand the slow thermal diffusion decreases the convection and hence results in a increase of the local Nusselt number, $-\theta^{\prime}(0)$. This phenomenon is more pronounced for higher values of Prandtl number, $P_{r}$.

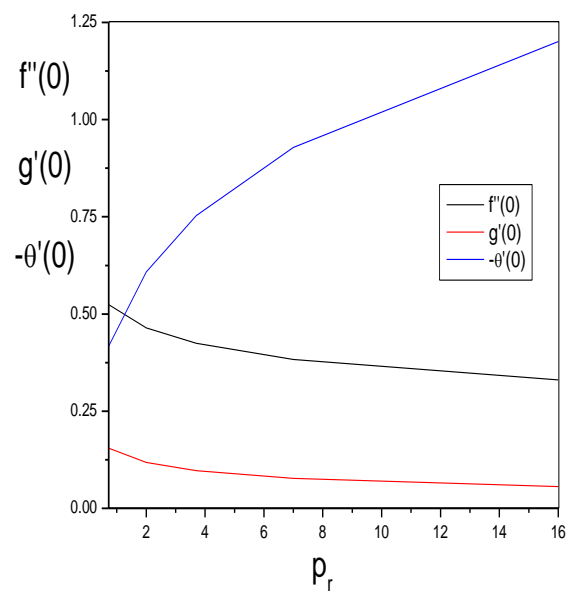

Fig. 35. Effects of $G$ on the local skin-friction coefficients and the local Nusselt number for

$$
\begin{gathered}
M=3.0, m=1.5, N_{1}=0.2, \\
G=2.0, P_{r}=0.72, B_{r}=0.0007
\end{gathered}
$$

Figure 36 illustrates the effect of Brinkman number, $B_{r}$, on the local skin-friction coefficients, $f^{\prime \prime}(0)$ and $g^{\prime}(0)$, and the local Nusselt number, $-\theta^{\prime}(0)$. As indicated in figure the skin friction force for tangential and lateral velocity is increasing with the increasing values of $B_{r}$. The Figure depicts that for larger values of $B_{r}, f^{\prime \prime}(0)$ and $g^{\prime}(0)$ is increasing highly. While increasing values of $B_{r}$ is found to decrease the values of $-\theta^{\prime}(0)$, as shown in the figure. Also it is observed that the negative local Nusselt number is attained for higher values of dissipation parameter, $B_{r}$. This phenomenon indicates that heat is transferred from the fluid to the plate in spite of excess of surface temperature over that of the free stream fluid.

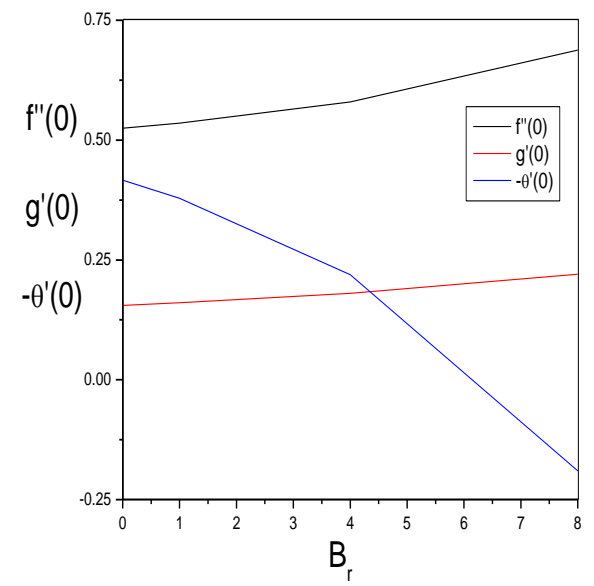

Fig. 36. Effects of $G$ on the local skin-friction coefficients and the local Nusselt number for $M=3.0, m=1.5, N_{1}=0.2$, $G=2.0, P_{r}=0.72, B_{r}=0.0007$.

\section{CONCLUSION}

In this paper, we have studied the MHD free convective heat and mass transfer flow in a micropolar fluid past a vertical plate with the effects of Hall current, Ohmic heating and suction/injection in the presence of a strong transverse magnetic field. The similarity equations are solved numerically using the Nachtsheim-Swigert shooting iteration technique. The results are presented graphically for several sets of the suction/injection parameter $\left(f_{w}\right)$, the magnetic field parameter $(M)$, the Hall parameter $(m)$, the material parameter $\left(N_{1}\right)$, the microrotational parameter $(G)$, the Prandtl number $\left(P_{r}\right)$ and the Brinkman number $\left(B_{r}\right)$. A systematic study on the effects of these parameters on the flow field, temperature field, the local skinfriction coefficients and the local Nusselt number is carried out. An excellent agreement is found between the present study and the results of the previously published data for some special values of $P_{r}$.

Some of the important findings of the study are:

- The local skin-friction coefficients are found to increase with increasing injection $\left(f_{w} \leq 0\right)$ while decrease with increasing $\operatorname{suction}\left(f_{w} \leq 0\right)$. But the 
local Nusselt number is increased with increasing suction.

- An increase in the value of the magnetic parameter $(M)$ is found to decrease the local skinfriction coefficient along the plate and the local Nusselt number. It is observed that an increase in the Hall parameter $(m)$ results in an increase the local skin-friction coefficient and the local Nusselt number.

- It is found that the tangential skin-friction coefficient is decreased and the normal skin friction coefficient, the local Nusselt number is increased with increasing material parameter, $N_{1}$.

- The local skin-friction coefficients along and normal to the plate are found to decrease and the local Nusselt number is found to increase with an increasing Prandtl number, $P_{r}$. The various values of chosen Prandtl number indicate that our results can be applied to several types of fluids.

- An increase in Brinkman number $\left(B_{r}\right)$ is found to decrease the local Nusselt number. But opposite is truewith the local skin-friction coefficients along and normal to the plate.

\section{ACKNOWLEDGEMENTS}

The first author (M. Ferdows) wishes to expresses his gratitude to the Department of Mathematics, University of Dhaka for enjoying study leave.

\section{REFERENCES}

Abo-Eldahab, E. M.and M. A. El Aziz (2005).Viscous dissipation and Joule heating effects on MHD-free convection from a vertical plate with power-law variation in surface temperature in the presence of Hall and ion-slip currents.Applied Mathematical modeling, 29(6), 579-595.

Aissa, W. A. and A. A. Mohammadein (2005). Joule heating effects on a micropolar fluid past a stretching sheet with variable electric conductivity .J. Compute. Appl. Mech., Vol. 6, p. 3-13.

Norfifah, B. and I. Anuar (2009). MHD stagnation flow of a micropolar fluid with prescribed wall heat flux. European journal of Scientific Research, 35(3), 436-443.

Bhargava, R.,L. Kumar, H. S. Takharand, R. S. Agarwal (2004). Quasi linearization of mixed convection micropolar flow near stagnation point with suction. International journal of heat and technology, 22(1), 103-112.

Cowling, T. G. (1957). Magneto-hydrodynamics . Inter science. Inc., New York, USA.
Chen, C. H., (2004). Combined heat and mass transfer in MHD free convection from a vertical surface with Ohmic heating and viscous dissipation. International Journal of Engineering Science, 42(7), p. 699-713.

Datta, N. and R. N. Jana (1976). Oscillatory magnetohydrodynamic flow past a flat plate with hall effects. Journal of the physical society of Japan, 40(5), 1469-1474.

El-Arabawy, H. A. M. (2003).Effect ofsuction/injection on the flow of a micropolar fluid past a continuously moving plate in the presence of radiation. International Journal of Heat and Mass Transfer, 46(8), 1471-1477.

Eringen,A. C. (1965). Theory of micropolar fluids. Journal of Mathematics and Mechanics. 16, 118

Gorla,R. S. R. (1992).Mixed convection in amicropolar fluid from a vertical surface with uniform heat flux. Int. J. Eng. Sci.,30, No.3, p. 349-358.

Gorla, R. S. R. and H. S. Takhar (1987). Free convection boundary layer flow of a micropolar fluid past a slender bodies. International Journal of Engineering Science, 25(8), 949962.

Gupta, A.S. (1960). On the flow of an electrically conducting fluid near an accelerated plate in the presence of a magnetic field. Journal of the physical society of Japan 15(10), 1894-1897.

Hady,F. M. (1996). On the solution of heat transfer to micropolar fluid from a non-isothermal stretching sheet with injection. International Journal of Numerical Methods for Heat and fluid Flow6(6), 99-104.

Hossanien, I. A. and F. M. Hady (1988). Micropolar boundary layer flow at astagnation point on a moving wall with suction and injection. Revue Roumainedes Sciences Techniques, Serie deMecanique Applique33, 439-447.

Hossain,M.A. and F. Khalil (1985). Effects of suction and hall currents on hydromagnetic flow near an accelerated porous plate. Journal of the physical society of Japan54(4), 13111316.

Jena, S. K. and M. M. Mathur (1981). Similarity solution for laminar free convection flow of thermo-micropolar fluid past anon-isothermal vertical flat plate. International Journal of Engineering Science 19(11), 1431-1439.

Khedr, M. -E. M., A. J. Chamka and M. Bayomi (2009). MHD flow of a micropolar fluid past a stretched permeable surface with heat generation or absorption. Nonlinear Analysis; Modeling and Control 14(1), 27-40. 
Katagiri, M. (1969). The effect of hall currents on the magnetohydrodynamic boundary layer flow past a semi-infinite flat plate. Journal of the physical society of Japan27(4), 1051-1059.

Mohammadein, A. A. and R. S. R. Gorla (2001). Heat transfer in a micropolar fluid over a stretching sheet with viscous dissipation and internal heat generation. International Journal of Numerical Methodsfor Heat and Fluid Flow11(1), 50-58.

Nachtsheim, P. R. and P. Swigert, P. (1965). Satisfaction of asymptotic boundary conditions in numerical solution of systems of non-linear equations ofboundary layer type.NASA TN D3004.

Niranjan,S., V. M. Soundalgekar and H. S. Takhar (1990). Free convection effects on HMD horizontal channel flow with Hall currents. IEEE transactions on plasma science18(2), 177-183.

Ortega-Torres,E. and M. Rojas- Medar (1998). The initial-value problem for the equations of magneto-micropolar fluid in a time dependent domain.Mat.Contemp15, 259-281.

Pop, I. and T. Watanabe (1994). Hall effects on magneto-hydrodynamic free convection about a semi-infinite vertical flat plate. International Journal of Engineering Science32(12),19031911.

Ram,P. C. (1995). Effects of Hall and ion-slip currents on free convective heat generating flow in a rotating fluid. International Journal of Energy Research19(5), 371-376.

Ram, P. C. and H. S. Takhar (1993). MHD free convection from an infinite vertical plate in a rotating fluid with Hall and ion slip currents. Fluid Dynamics Research 11(3), 99-105.

Ram, P.C. (1988). Hall effects on the hydromagnetic free convective flow and mass transfer through a porous medium bounded by an infinite vertical porous plate with constant heat flux. International Journal of Energy Research 12(2), 227-231.
Rahman, M. M. and M. A. Sattar (2006). Magnetohydrodynamic convective flow of a micropolar fluid past a continuously moving vertical porous plate in the presence of heat generation/absorption, ASME Journal of Heat Transfer128( 2), 142-152.

Rees, D. A.S. and I. Pop (1998). Free convection boundary layer flow of micropolar fluids from a vertical flat plate.IMA Journal of Applied Mathematics 61(2), 179-197.

Sato, H. (1961). The hall effect in the viscous flow of ionized gas between parallel plates under transverse magnetic field. Journal of the physical society of Japan 16(7), 1427-1433.

Seddek, M. A. and M. S. Abdelmeguid (2004). Hall and Ion-Slip effects on magneto-micropolar fluid with combined forced and free convection in boundary layer flow over a horizontal plate. Journal of the Korean Society for Industrial and Applied Mathematics 8(2), 51-73.

Singh D. (1964). Unsteady hydro-magnetic free convection flow past a vertical infinite flat plate. Journal of the physical society of Japan19(5), 751-755.

Sparrow, E. M. and W. J. Minkowycz (1962). Buoyancy effects on horizontal boundary-layer flow and heat transfer. International Journal of Heat and Mass Transfer 5(6), 505-511.

Soundalgekar, V. M. and H. S. Takhar (1983). Flow of a micropolar fluid on a continuously moving plate. International Journal of Engineering Science 21(8), 961-965.

Yian, L. Y., N. Amin and I. Pop (2007). Unsteady case for boundary layer flow of a micropolar fluid near a stagnation point with uniform suction/ injection. Journal Teknologi, 46(C), 15-32. 